\title{
Adaptive Charging Strategy With Temperature Rise Mitigation and Cycle Life Extension for Li-ion Batteries
}

\author{
Shun-Chung Wang, Guan-Jhu Chen, and Yi-Hua Liu
}

\begin{abstract}
Charging battery with a large C-rate current to shorten the charging time (CT) will induce the drastic electrochemical reaction, and thus bring about the significant temperature rise (TR), energy loss, performance degradation, and safety concern as well. To tackle this problem, an adaptive charging strategy with TR mitigation and cycle life extension is proposed in this study. Based on the relationship between the charging current and remaining state of charge (RSOC) which is extracted experimentally, a baseline charging current is determined first. To control the temperature rise further, a fuzzy TR controller (FTC) is devised to fine-tune the charging current according to the temperature gradient. Thus an adaptive charging current with temperature rise suppression mechanism can be generated dynamically in the entire charging process. The proposed charging strategy is validated by means of experimental studies and compared with the conventional constant current-constant voltage (CC-CV) method. The results show that the average temperature rise, charging efficiency, and estimated cycle life have $31.24 \%, 2.06 \%$, and $57.3 \%$ of improvement respectively as compared with that of the conventional $\mathrm{CC}$ CV obtained.
\end{abstract}

Index Terms-Adaptive charging strategy, cycle life extension, fuzzy temperature-rise controller.

\section{NomenClature}

$\begin{array}{ll}C T & \text { Charging time. } \\ T R & \text { Temperature rise. } \\ \text { SOC } & \text { State of charge. } \\ R S O C & \text { Remaining state of charge. } \\ F T C & \text { Fuzzy temperature-rise controller. } \\ C C-C V & \text { Constant current-constant voltage. } \\ H E V & \text { Hybrid electric vehicle. } \\ E V & \text { Electric vehicle. } \\ E S S & \text { Energy storage system. } \\ \text { Li-ion } & \text { Lithium-ion. } \\ R C C & \text { Remaining capacity charging. } \\ 4 S 2 P & \text { Four series two parallel. }\end{array}$

Manuscript received August 1, 2018. This work was financially supported by the Taiwan Building Technology Center from the Featured Areas Research Center Program within the framework of the Higher Education Sprout Project by the Ministry of Education in Taiwan.

S. -C. Wang is with the Department of Electrical Engineering, Lunghwa University of Science and Technology, Taoyuan, 33306 Taiwan (e-mail: wangsc@ mail.lhu.edu.tw).

G. -J. Chen and Y. -H. Liu are with the Department of Electrical Engineering, National Taiwan University of Science and Technology, Taipei, 10607 Taiwan (e-mail: D10707003@mail.ntust.edu.tw; yhliu@mail.ntust.edu.tw).

Digital Object Identifier 10.24295/CPSSTPEA.2018.00020

\author{
$S B C \quad$ Synchronous buck converter. \\ $M C U \quad$ Microcontroller unit. \\ GUI Graphic user interface. \\ $I^{2} C \quad$ Inter-integrated circuit. \\ $A D C \quad$ Analog to digital converter. \\ FIR Finite impulse response. \\ PID Proportional integral differential. \\ $D P W M \quad$ Digital pulse width modulation. \\ CTR Charging time ratio. \\ $M F \quad$ Membership function. \\ UOD Universe of discourse. \\ COS Center of sum. \\ RCFTC Remaining capacity with FTC.
}

\section{INTRODUCTION}

1 O deal properly with problems of energy shortage and global warming, the objective of cut in carbon emissions intended by governments is getting stricter. As a result, powertrain electrification has been regarded as the most promising substitute for a vehicle driven by an internal combustion engine to fulfill the international anticipation on eco-friendly and energy-efficient transportation [1]-[3]. Accordingly, automakers now are devoted to developing vehicle electrification using electronic components or subsystems in the form of hybrid electric vehicles or electric vehicles (HEVs/EVs). Power battery is a key component for the success of transportation electrification, in which the relevant issues concerned most by users include safety, endurance anxiety, charging time, and cost-effectiveness. Therefore, advanced energy storage systems (ESSs) together with intelligent energy management algorithms will be the essential technology for the electrification in the next generation EVs [4].

Commercial batteries based on Lithium-ion (Li-ion) chemistry, in particular the $\mathrm{LiFePO} 4$ one, has been confirmed that their performances are very suitable for use in the ESS due to many remarkable characteristics [5], [6]. For a battery storage system in EVs, a well-designed on-board charger [7]-[9] must be equipped with advanced charging strategies to ensure efficient and safe operations. On the other hand, excessive fast charging not only gives rise to the extreme electrochemical stresses but also results in the aging aggravation and significant performance degradation [10], [11]. These degenerative effects arise from the increasing internal resistance of the battery caused by substantial temperature rise due to the increase in energy losses. The battery temperature rise is closely connected 
to the charging profile used and it is a competing factor to the charging time and energy loss generally. Nowadays, one of the commonly adopted methods for charging Li-ion batteries is the constant current-constant voltage (CC-CV) strategy [12]. This method applies a fixed current to charge the battery in $\mathrm{CC}$ mode till a predefined voltage limit is reached, and then the charging process is switched to CV mode whose voltage is kept at the predefined voltage until the end-of-charge condition, which drops the current below a cut-off threshold, is met. The CC-CV charging method is easy to implement and can fully charge the battery. However, its performance is related to the pre-defined limit values. Therefore, how to select a proper charging current in the CC stage and the best time to transit $\mathrm{CC}$ to $\mathrm{CV}$ to reach preferable charging efficiency is still a challenging problem [13]. In addition, energy loss increased in $\mathrm{CC}$ mode leads to higher temperature rise. The $\mathrm{CV}$ stage substantially extends the charging time and thus will degrade the charging efficiency. Fast charging has always been an indispensable design of the battery employed in EVs [14]-[16]. Hence, how to make fast charging achievable yet still maintain safety, efficacy and longevity is a substantial challenge.

To meet the rapid charging criteria, various ameliorations or variants based on the standard CC-CV method have been proposed [17]-[19]. Experimental results demonstrate that these methods can attain a charging profile similar to the $\mathrm{CC}-\mathrm{CV}$ in a simple and low-cost way, and obtain shorter charging time and higher charging efficiency than the standard CC-CV method. A series of studies on charging strategy, profile, or topology to meet the fast charging criteria were addressed by Chen et al. [20]-[22] Improvements in charging efficiency and speed have been verified experimentally by these devised schemes. Comparing with the standard $\mathrm{CC}-\mathrm{CV}$, the multistage constant current charging method can offer better charging efficiency [23]-[25]. Intelligent control algorithms, such as fuzzy control [26], neural network [27], gray-prediction control [28], and genetic approaches [29], have also been adopted to elevate the accuracy of the parameter estimation and operating performance of the charger. Accurate characterization of the battery parameter and behavior is necessary for these algorithms. Besides, a model which exhaustively reflects the battery dynamic behavior in real time is difficult to construct, because the reaction process of the electrochemical, thermoelectric, and aging phenomena are sophisticated and unmeasurable. Therefore, development in charging modes alone could not promise to obtain best charging profiles and raise the charging efficacy significantly. Furthermore, the cycle life issues are seldom discussed in these researches. In recent, studies on optimal charging strategies based on battery equivalent circuit model, electrochemical and/or electrothermal models integrated with optimization control algorithms to find the optimum charging pattern out have become a focus. Such a problem can be regarded as a combinatorial optimization problem which is difficult to resolve with traditional methods. Several optimization techniques, such as particle swarm optimization (PSO) [30], non-dominated sorting genetic algorithm II [31], the ant colony system [32], and advanced optimal approaches with battery health-aware charging strategies formulated by the analysis and computation of accurate battery behavior models [10], [33][37] have been applied to obtain the best compromise among the competing objectives and achieve charging performance amelioration. However, sophisticated models with real-time parameters update are necessary. High implementation complexity and computational burden make these optimal approaches more difficult to realize online and use low-end microprocessor chips. The Taguchi-based approach cooperated with fuzzy control have also been validated to be feasible and effective in searching for the optimal charging pattern of the five-step CC charging method [38]-[40].

In this paper, a remaining capacity charging method with fuzzy TR control is proposed to determine proper charging currents adaptively as facing with different charging conditions. A corresponding baseline charging current is first selected depending on the relationship between the current SOC and charging current that is extracted from actual charging and discharging test data. Then an FTC is designed to fine-tune the charging current according to the battery temperature variation. By adding the fine-tuning incremental current to the baseline one, a charging current with TR alleviation can be obtained. The proposed adaptive charging strategy can regulate the charging current adaptively on the basis of changes in current SOC status and battery temperature to achieve performance promotion during the entire charging phase. Moreover, the adverse condition of using high C-rate current to charge battery with high SOC can be avoided. In addition, without need to model the exhaustive battery behavior, depending on the change of the charging condition, the proposed charging method has taken the nonlinearity of the battery electrothermal behavior and the circuit parameter non-ideality into account to attain the temperature rise suppression effectively via charging current dynamic regulation using fuzzy-based decision-making mechanism. The rest of this paper is organized as follows. Section II introduces the architecture of the proposed charger. Fundamental and implementation of the proposed remaining capacity charging and fuzzy TR control strategy are described in Section III. Section IV shows experimental results, and comparisons with the traditional $\mathrm{CC}-\mathrm{CV}$ method are given to highlight the performance improvement of the studied charging method. Finally, this paper is concluded in Section V.

\section{Battery Charger Architecture}

Fig. 1 shows the architecture of the studied digitally-controlled Li-ion battery pack charger. The input voltage of the charger derived from a front-end ac-dc rectifier with a regulable output voltage which is adaptable to the applications of battery-powered devices. The battery pack used in this paper is made up of 4-series-2-parallel (4S2P) Li-ion battery cells, in which each cell has nominal capacity of $2200 \mathrm{mAh}$. The range of the pack voltage is $12 \mathrm{~V} \sim 16.8 \mathrm{~V}$, and all cells are screened beforehand to ensure that each cell has the similar characteristics. The synchronous buck converter (SBC) was adopted as the power stage. The gas gauge IC bq20Z45 [41] was used to estimate the SOC of the battery pack. Temperatures of the bat- 


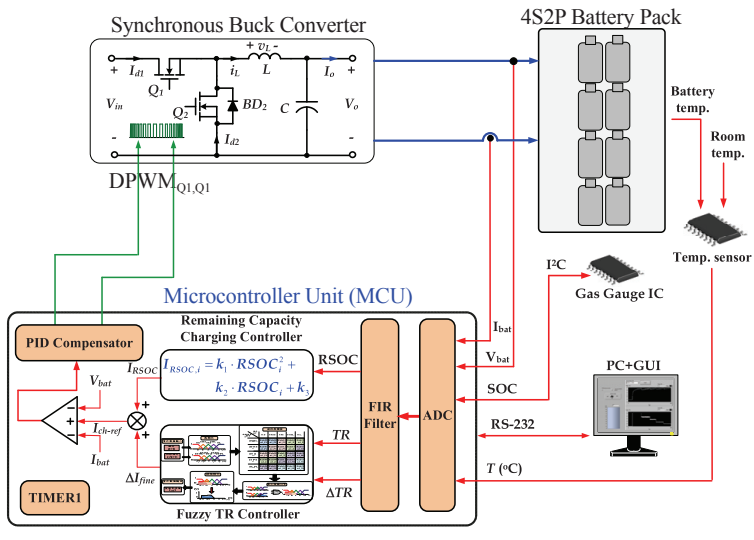

Fig. 1. Proposed charger configuration.

tery exterior and room were detected by the temperature sensor. The proposed adaptive charging approach was implemented by a low-cost dsPIC microcontroller unit (MCU) from Microchip [42]. The firmware written in the MCU carries out the remaining capacity charging strategy, fuzzy temperature rise control, and quantizes the detected battery voltage $V_{b a t}$, current $I_{b a t}$, SOC, battery and room temperatures $T\left({ }^{\circ} \mathrm{C}\right)$, and the feedback signals to reduce the circuit complexity.

The PC with developed graphic user interface (GUI) records and monitors various battery data and waveforms online during the charging process. The SOC gauge IC communicates with the MCU through the inter-integrated circuit $\left(\mathrm{I}^{2} \mathrm{C}\right)$ protocol, andthe connection between the MCU and PC is via the universal asynchronous receiver transmitter standard RS-232. The data of the RSOC and TR are sampled and quantized by the analog to digital converter (ADC) and filtered by finite impulse response (FIR) filter, respectively, and then these data are sent to the remaining capacity charging controller and fuzzy TR controller, which are realized by firmwares in the MCU. Based on the variation of the pack RSOC and temperature, the RCC controller outputs a corresponding coarse-tuning current and the FTC outputs a fine-tuning incremental charging current $\Delta I_{\text {fine }}$, which is added to the coarse-tuning current to generate areference value $I_{c h \text {-ref }}$ that is the desired charging profile. Comparing the reference value with actual charging current, an error is obtained and routed to the proportional integral differential (PID) compensator to calculate the required duty cycles of the digital pulse width modulation (DPWM) gating signals. Simultaneously, the data are recorded by PC and displayed on the GUI.

In low-voltage and high-current applications, the power consumption of the diode in buck converter due to the forward voltage drop $V_{F D}$ and the equivalent resistance $R_{D}$ has become one of the main reasons for the decrease in efficiency. The conduction loss will increase with the increase in output current. An SBC, which replaces the diode with a synchronous rectifier (a MOSFET with very low on-resistance $R_{d s-o n}$ ), is adopted to further reduce the conduction loss of the diode. As shown in Fig. 1 , the conduction loss and switching loss of switch $Q_{1}$ can be expressed as

$$
P_{\text {con- } Q_{1}}=D I_{r m s}^{2} R_{d s 1-o n}
$$

$$
P_{s w-Q_{1}}=\frac{1}{2} V_{i n} I_{r m s}\left(t_{r i}+t_{f v}\right) f_{s}
$$

Where $D$ is the duty cycle, $I_{r m s}$ is the RMS value of the switch current, $t_{r i}$ is the current rise time, $t_{f v}$ is the voltage fall time, and $f_{s}$ is the switching frequency. The conduction losses of the synchronous rectification MOSFET $Q_{2}$ and the conventional diode can be expressed by

$$
\begin{gathered}
P_{\text {con- } Q_{2}}=\underbrace{(1-D) I_{r m s}^{2} R_{d s 2-o n}}_{\text {MOSFET } Q_{2}}+\underbrace{2 I_{r m s} V_{F B D_{2}} t_{\text {delay }} f_{s}}_{\text {body diode } B D_{2}} \\
P_{D}=V_{F D} I_{r m s}(1-D)+(1-D) I_{r m s}^{2} R_{D}
\end{gathered}
$$

Where $V_{F B D 2}$ is the turn-on voltage drop of the body diode $B D_{2}$ in $Q_{2}$, and $t_{\text {delay }}$ is the turn-on delay time of the body diode.

When $Q_{2}$ is on, the relationship between the RMS current $I_{r m s}$ and $I_{o}$ is

$$
I_{r m s}=\frac{\pi}{4} I_{o}
$$

Then, in (3), if the loss of the body diode is neglected, the power consumption caused by the resistor $R_{d s 2-o n}$ can be approximated as

$$
P_{\text {con- } Q_{2}}=(1-D)\left(\frac{\pi}{4} I_{o}\right)^{2} R_{d s 2-o n}=(1-D) P_{o} \frac{\pi^{2} \cdot R_{d s 2-o n}}{16 \cdot R}
$$

Substituting (5) into (4), the diode conduction loss can be obtained by

$$
P_{D}=(1-D) P_{o}\left(\frac{\pi^{2}}{16} \frac{R_{D}}{R}+\frac{\pi}{4} \frac{V_{F D}}{V_{o}}\right)
$$

From (6) and (7), if $R_{D}=R_{d s 2-o n}$, then the diode will have one more forward voltage drop loss than the synchronous rectifier. Therefore, if the output is low voltage and large current, the efficiency of the buck converter with conventional diode will be much lower than that of using the synchronous rectifier. According to the rating of the battery pack, an $85 \mathrm{~W}$ charger adopting the above-mentioned topology was designed. The design specifications of the charger are listed in TABLE I.

\section{Proposed Charging Strategy}

A novel adaptive charging profile control strategy combining the residual capacity charging with a fuzzy temperature-rise controller is proposed in this paper. In order to achieve the control objectives, firstly it is necessary to know the time required for fully charging battery with different charging $\mathrm{C}$ rates at different remaining capacities and the temperature rise obtained by the same charging process through the experimental tests. Then the relationships between the CT and RSOC as well as the TR and RSOC with different charging $\mathrm{C}$ rates can be derived, respectively. Next, a commensurate charging current $I_{R S O C}$ (or called corase-tuning charging current) can be determined prop- 
TABLE I

Design Specifications of the Studied Charger

\begin{tabular}{lc}
\hline \hline Input voltage $\left(V_{\text {in }}\right)$ & $24 \mathrm{~V}$ \\
Output voltage $\left(V_{o}\right)$ & $12 \sim 16.8 \mathrm{~V}$ \\
Output power $\left(P_{o}\right)$ & $85 \mathrm{~W}$ \\
Efficiency $(\eta)$ & $>90 \%$ \\
Switching frequency $\left(f_{s}\right)$ & $100 \mathrm{kHz}$ \\
Output voltage ripple $\left(\Delta V_{o} / V_{o}\right)$ & $<5 \%$ \\
Output current ripple $\left(\Delta I_{o} / I_{o}\right)$ & $<20 \%$ \\
\hline \hline
\end{tabular}

erly based on the current RSOC gauged correspondingly, thus the situation of charging high SOC battery with high $\mathrm{C}$ rate can be avoided. The CT required for full charge can also be shorten because the selected corase-tuning charging current has a good charging time ratio (CTR), which is defined as the ratio of full charge time required for $1 \mathrm{C}$ charging current to that required for the selected coarse-tuning current in the CC-CV method. In addition, in order to further control the battery temperature rise, a fuzzy temperature-rise controller is developed to fine tune the charging current based on the dynamic change in battery temperature. When the battery temperature rises, the charging current is reduced, otherwise, the charging current is increased. By imposing the fine-tuning current $\Delta I_{\text {fine }}$ on the coarse-tuning current $I_{R S O C}$, the desired charging current with TR control can be obtained. Thus the battery can be fully charged in an acceptable charging time, and the temperature rise is controllable to relieve the performance degradation.

The proposed method is adaptable because, during the charging process, the charging current can be dynamically regulated according to the changes of the battery SOC status and battery temperature to achieve TR alleviation and lifespan extension. That is, a proper baseline (coarse) charging current, in accordance with the gauge of the current RSOC, can be first determined through the studied curve-fitting relationship between the charging current and the RSOC variation. Thus the adverse condition of using high C-rate current to charge battery with high SOC can be avoided. Next, an incremental current is generated through the devised fuzzy temperature controller and imposed on the coarse current to finely regulate the charging current to control the temperature variation further. Therefore, the adaptability of the presented method derives from the charging profile can be controlled dynamically by following the changes of current charging state and temperature to fully charge battery with reasonable charging time and low temperature rise. In the following subsections, the philosophy of the studied remaining capacity charging method and the design principle of the FTC are described respectively.

\section{A. Philosophy of Remaining Capacity Charging}

The remaining capacity charging (RCC) method can measure a battery current SOC to adjust how much charging current must be used. Before implementing this method, several experiments must be done to determine the best charging profil required for each gauged SOC. Through the experimental test, relevant information and data for fully charging a battery at dif- ferent remaining capacity with different $\mathrm{C}$ rates can be acquired, then the relationships between the CT and RSOC as well as the TR and RSOC can be extracted from the meaured records. Accordingly, for a battery with any initial RSOC, an evaluation criterion for determination of the suitable charging current to reach the acceptable CT and lower TR can be established via the analysis and exploration of the derived relationship among the charging time, temperature rise, and remaining state of charge. To obtain the data required for the RCC method, different $\mathrm{C}$-rate $(0.2 \mathrm{C} \sim 1 \mathrm{C}$ with a step of $0.1 \mathrm{C})$ charging currents are used to charge a battery with different initial RSOCs $(0 \% \sim 100 \%$ with a step of 10\%). Using Fig. 2 as an example to illustrate the experimental test procedure. In Fig. 2(a), assuming that the battery has $40 \%$ of initial RSOC. The test process needed to charge the battery from $70 \%$ to $100 \%$ of RSOC with $1 \mathrm{C}$ rate is shown in Fig. 2(b). from Fig. 2(a), the battery is first charged with $1 \mathrm{C}$ rate until the voltage reaches $4.2 \mathrm{~V}$, the $\mathrm{CV}$ mode with $4.2 \mathrm{~V}$ is run until the current drops below $0.01 \mathrm{C}$, then stop charging and rest 1.5 hours. The next, discharge with $0.1 \mathrm{C}$ is carried out. After discharging for 3 hours, stop discharging and rest 1.5 hours. At this time, the battery RSOC is about $70 \%$. The next step is to charge the battery with $1 \mathrm{C}$ rate again. As the battery voltage reaches $4.2 \mathrm{~V}$, it is switched to $\mathrm{CV}$ mode until the end of charging is reached, then stop charging and rest 1.5 hours. From this test, the $\mathrm{CT}$ and TR required for charging the battery from $70 \%$ to $100 \%$ of RSOC with $1 \mathrm{C}$ rate can be measured. Similarly, other datum acquired for charging battery from different percent remaining capacity to $100 \%$ using different $\mathrm{C}$ rates can be obtained by running the similar test procedures.

As mentioned above, the test results of the CT and RT obtained by charging a battery with specified initial RSOCs to full charge using different $\mathrm{C}$ rates are shown in TABLE II and Fig. 3, respectively. From the measured charging time listed in TABLE II, a charging time ratio (CTR) is defined as the ratio of the fullcharge time required for $1 \mathrm{C}$ rate to those required for the other $0.2 \mathrm{C}$ to $0.9 \mathrm{C}$ ones. The calculated CTR and the differences of full-charge tme between the $0.2 \mathrm{C}$ to $0.9 \mathrm{C}$ and $1 \mathrm{C}$ is tabulated in TABLE III, in which the $\Delta \mathrm{t}$ is the charging-time differencebetween charging with $0.2 \mathrm{C} \sim 0.9 \mathrm{C}$ and with $1 \mathrm{C}$, and the corresponding CTR cureves is ploted in Fig. 4. The design objective is to shorten the $\mathrm{CT}$ as possible but still maintain the acceptable TR and satisfy safety constraints, therefore the CTRs more than 0.9 (coloring fields in TABLE III) are chosen as the evaluation criterion in this study. It can be noted that, from TABLE III, when the remaining capacity is $0 \%$, the difference of charging time between using $0.9 \mathrm{C}$ charge and using $1 \mathrm{C}$ charge is only 5 minutes and 37 seconds; additionally, as the remaining capacity is $90 \%$, the difference of CT between using $0.4 \mathrm{C}$ charging and $1 \mathrm{C}$ charging is only 2 minutes and 50 seconds. As a result, there is no need to charge battery using the highest $\mathrm{C}$ rate always, and a proper charging current can be determined based on the current remaining capacity, which can reduce the adverse effect of excessive TR on battery life.The $4400 \mathrm{mAh}$ battery pack was used in this study to do experimental confirmation. Based on the evaluation criterion as shown in TABLE III, the charging currents with CTRs over 0.9 are listed in TABLE IV. 
TABLE II

Required Charging Time for Fully Charging Battery Pack

\begin{tabular}{|c|c|c|c|c|c|c|c|c|c|}
\hline SOC & $0.2 \mathrm{C}$ & $0.3 \mathrm{C}$ & $0.4 \mathrm{C}$ & $0.5 \mathrm{C}$ & $0.6 \mathrm{C}$ & $0.7 \mathrm{C}$ & $0.8 \mathrm{C}$ & $0.9 \mathrm{C}$ & $1 \mathrm{C}$ \\
\hline $0 \%$ & $5: 33: 27$ & $4: 00: 21$ & $3: 13: 28$ & $2: 42: 03$ & $2: 25: 16$ & $2: 12: 11$ & $2: 03: 30$ & $1: 56: 07$ & $1: 50: 30$ \\
\hline $10 \%$ & 5:03:58 & $3: 41: 56$ & $3: 00: 16$ & $2: 21: 46$ & $2: 17: 17$ & 2:05:20 & $1: 57: 13$ & $1: 52: 29$ & $1: 46: 59$ \\
\hline $20 \%$ & $4: 33: 35$ & $3: 19: 46$ & 2:44:08 & $2: 20: 43$ & $2: 07: 27$ & $1: 57: 02$ & 1:49:03 & $1: 48: 13$ & $1: 40: 52$ \\
\hline $30 \%$ & $3: 53: 20$ & $2: 58: 44$ & $2: 28: 44$ & 2:08:06 & $1: 56: 07$ & $1: 47: 50$ & 1:43:19 & $1: 39: 28$ & $1: 33: 59$ \\
\hline $40 \%$ & $3: 31: 53$ & 2:39:06 & 2:01:51 & $1: 55: 18$ & 1:46:17 & 1:38:03 & $1: 34: 41$ & $1: 32: 13$ & $1: 27: 17$ \\
\hline $50 \%$ & $2: 51: 33$ & $2: 18: 56$ & 1:46:38 & $1: 42: 59$ & 1:34:56 & 1:30:01 & $1: 27: 18$ & $1: 24: 13$ & $1: 21: 02$ \\
\hline $60 \%$ & $2: 31: 39$ & $1: 56: 43$ & $1: 38: 25$ & $1: 29: 57$ & $1: 25: 13$ & $1: 20: 38$ & $1: 18: 41$ & $1: 16: 50$ & $1: 13: 52$ \\
\hline $70 \%$ & $1: 49: 32$ & $1: 32: 58$ & $1: 22: 33$ & $1: 15: 43$ & $1: 11: 51$ & 1:08:46 & $1: 07: 49$ & $1: 04: 57$ & $1: 04: 28$ \\
\hline $80 \%$ & $1: 24: 13$ & $1: 10: 04$ & $1: 04: 05$ & $0: 58: 36$ & $0: 57: 41$ & $0: 54: 27$ & $0: 54: 18$ & $0: 54: 14$ & $0: 53: 07$ \\
\hline $90 \%$ & $0: 52: 21$ & $0: 47: 01$ & $0: 44: 27$ & $0: 42: 39$ & $0: 42: 12$ & $0: 42: 00$ & $0: 41: 50$ & $0: 41: 45$ & $0: 41: 38$ \\
\hline
\end{tabular}

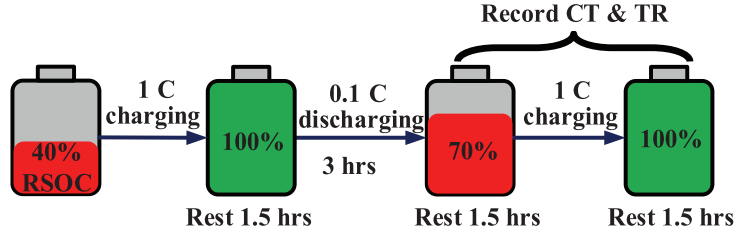

(a)

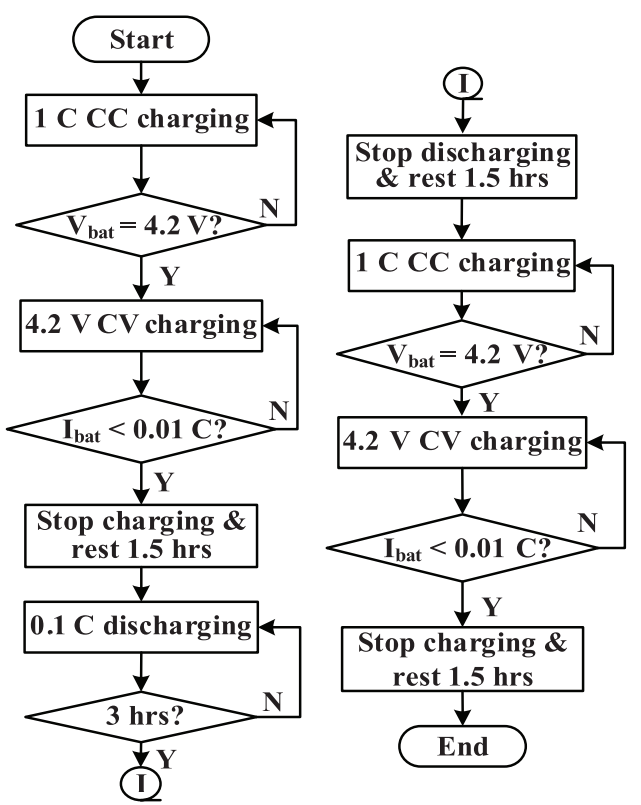

(b)

Fig. 2. Experimental test procedure: (a) Illustration for testing $70 \%$ residual capacity using $1 \mathrm{C}$ rate for battery with $40 \%$ initial capacity; (b) Test procedure flowchart.

Where the $\mathrm{I}_{\text {bat }}$ is the charging current at $1 \mathrm{C}$, i.e. $\mathrm{I}_{\mathrm{bat}}=4.4 \mathrm{~A}$ in this paper. The given charging current $I_{R S O C, i}$ is equivalent to the desired coarse-tuning current whose CTR is greater than 0.9 at each corresponding RSOC in this research. Furthermore, to fulfill practical charging application, a mathematical model is built from the limited experimental samples. The curve fitting was employed to formulate the relationship between the $I_{R S O C, i}$ and the $\mathrm{RSOC}_{i}$. Fig. 5 illustrates the dependence of the desired charging current on different RSOCs. The curve function fitted

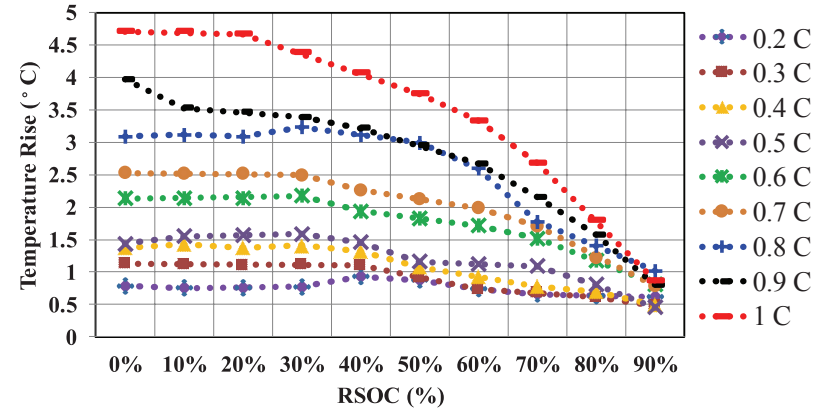

Fig. 3. Measured temperature rise obtained by fully charging battery pack.

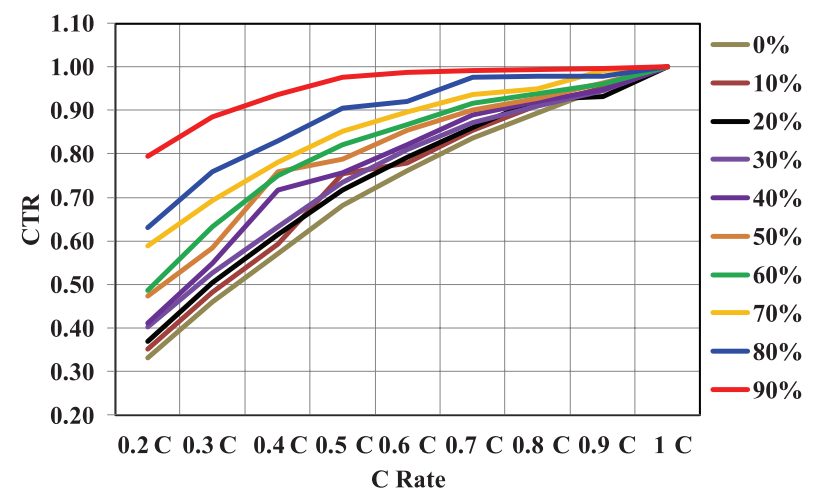

Fig. 4. Plot of CTR curves under different initial RSOCs.

by the quadratic polynomial is expressed by

$$
I_{R S O C, i}=k_{1} R_{S O C}^{2}+k_{2} R_{S O C}+k_{3}
$$

For the specifications of the battery pack used here, the coefficient $k_{1}$ is $-2.5 \times 10^{-4}, k_{2}$ is 0.001167 , and $k_{3}$ is 3.74 .

\section{B. Design Principle of Fuzzy Temperature-Rise Controller}

In order to alleviate the battery aging effect, a fuzzy temperature-rise controller (FTC) is designed to fine modulate the charging current. This fine tuning current is imposed on the coarse-tuning current to produce the desired charging current, which features ability of temperature rise control. In other 
TABLE III

CTR and Difference of Full-Charge Time with $1 \mathrm{C}$

\begin{tabular}{|c|c|c|c|c|c|c|c|c|c|c|}
\hline SOC & $0.2 \mathrm{C}$ & $0.3 \mathrm{C}$ & $0.4 \mathrm{C}$ & $0.5 \mathrm{C}$ & $0.6 \mathrm{C}$ & $0.7 \mathrm{C}$ & $0.8 \mathrm{C}$ & $0.9 \mathrm{C}$ & $1 \mathrm{C}$ & $\Delta \mathrm{t}$ \\
\hline $0 \%$ & 0.33 & 0.46 & 0.57 & 0.68 & 0.76 & 0.84 & 0.89 & 0.95 & 1 & $0: 05: 37$ \\
\hline $10 \%$ & 0.35 & 0.48 & 0.59 & 0.75 & 0.78 & 0.85 & 0.91 & 0.95 & 1 & $0: 10: 13$ \\
\hline $20 \%$ & 0.37 & 0.50 & 0.61 & 0.72 & 0.79 & 0.86 & 0.92 & 0.93 & 1 & 0:08:11 \\
\hline $30 \%$ & 0.40 & 0.53 & 0.63 & 0.73 & 0.81 & 0.87 & 0.91 & 0.94 & 1 & 0:09:20 \\
\hline $40 \%$ & 0.41 & 0.55 & 0.72 & 0.76 & 0.82 & 0.89 & 0.92 & 0.95 & 1 & $0: 07: 24$ \\
\hline $50 \%$ & 0.47 & 0.58 & 0.76 & 0.79 & 0.85 & 0.90 & 0.93 & 0.96 & 1 & 0:08:59 \\
\hline $60 \%$ & 0.49 & 0.63 & 0.75 & 0.82 & 0.87 & 0.92 & 0.94 & 0.96 & 1 & 0:06:46 \\
\hline $70 \%$ & 0.59 & 0.69 & 0.78 & 0.85 & 0.90 & 0.94 & 0.95 & 0.99 & 1 & $0: 07: 23$ \\
\hline $80 \%$ & 0.63 & 0.76 & 0.83 & 0.91 & 0.92 & 0.98 & 0.98 & 0.98 & 1 & 0:05:29 \\
\hline $90 \%$ & 0.80 & 0.89 & 0.94 & 0.98 & 0.99 & 0.99 & 1.00 & 1.00 & 1 & $0: 02: 50$ \\
\hline
\end{tabular}

TABLE IV

Corresponding Charging Current as CTR Above 0.9

\begin{tabular}{ccccc}
\hline \hline$R S O C_{i}$ & $0 \%$ & $10 \%$ & $20 \%$ & $30 \%$ \\
$I_{R S O C, i}$ & $I_{R S O C, 0}=0.9 \mathrm{I}_{\mathrm{bat}}$ & $I_{R S O C, 1}=0.8 \mathrm{I}_{\mathrm{bat}}$ & $I_{R S O C, 2}=0.8 \mathrm{I}_{\mathrm{bat}}$ & $I_{R S O C, 3}=0.8 \mathrm{I}_{\mathrm{bat}}$ \\
$R S O C_{i}$ & $50 \%$ & $60 \%$ & $70 \%$ & $I_{R S O C, 4}=0.8 \mathrm{I}_{\mathrm{bat}}$ \\
$I_{R S O C, i}$ & $I_{R S O C, 5}=0.7 \mathrm{I}_{\mathrm{bat}}$ & $I_{R S O C, 6}=0.7 \mathrm{I}_{\mathrm{bat}}$ & $I_{R S O C, 7}=0.6 \mathrm{I}_{\mathrm{bat}}$ & $I_{R S O C, 8}=0.5 \mathrm{I}_{\mathrm{bat}}$ \\
\hline
\end{tabular}

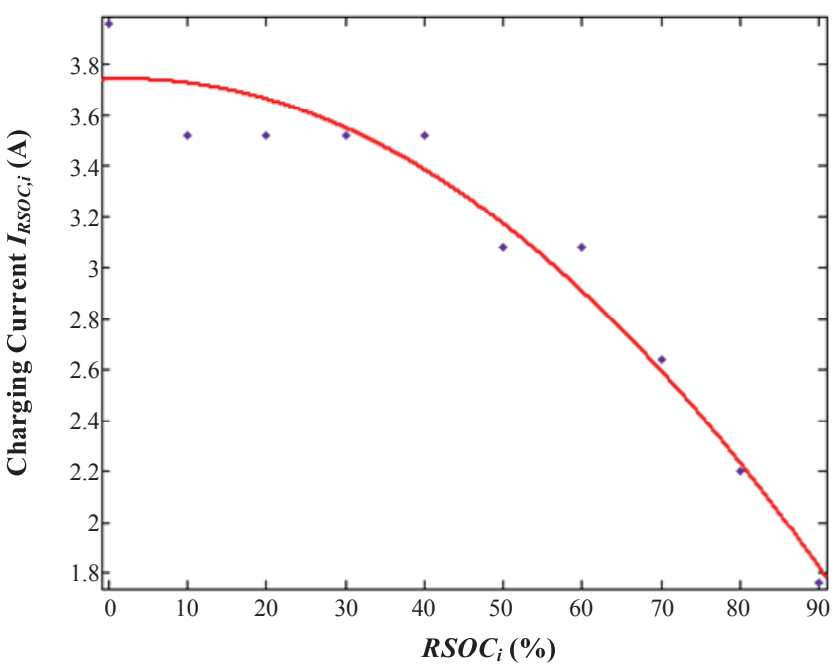

Fig. 5. Plot of charging current versus RSOC and the fitting curve.

words, an incremental current $\Delta I_{\text {fine }}$ was generated by the fuzzy temperature controller and added to the $I_{R S O C, i}$ to further regulate the charging current according to the variation of the working temperature. When the TR was increasing during charging process, the charging current will be reduced for a $\Delta I_{\text {fine }}$ step consecutively to drop the temperature rise and diminish impact on the battery. On the other hand, as the TR was decreasing, the charging current will be increased for a $\Delta I_{\text {fine }}$ step each time to shorten the charging time.

The scheme of the proposed FTC is shown in Fig. 6. From Fig. 6, the input variables of the FTC are the temperature rise (TR) and the 2-second temperature rise ( $\triangle T R$ ). In which the TR was defined as the difference between the battery surface temperature and the room temperature.The $\Delta \mathrm{TR}$ was the difference

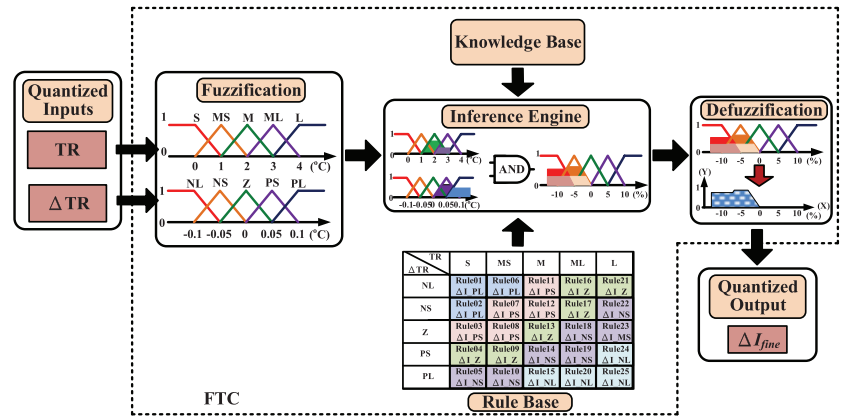

Fig. 6. Scheme of the proposed FTC.

between the present TR and the TR before two seconds. The output variable was the incremental current $\Delta I_{\text {fine }}$. The Mamdani-type Minimum inferential method cooperating with the center of sum (COS) defuzzification procedure was utilized in this paper to obtain the crisp output.The membership functions (MFs) corresponding to the TR, $\Delta \mathrm{TR}$, and $\Delta I_{\text {fine }}$ are illustrated in Fig. 7(a)-(c), respectively. According to the experience of the lithium-ion battery charging, five fuzzy subsets are designated for the input and output variables respectively. The universe of discourse (UOD) in the MFs of TR and $\triangle \mathrm{TR}$ aredefined on the domain $\left[0^{\circ} \mathrm{C}, 4^{\circ} \mathrm{C}\right]$ and $\left[-0.1^{\circ} \mathrm{C}, 0.1^{\circ} \mathrm{C}\right]$, respectively. On the other hand, the UOD of the output variable is defined on the domain [-20\%, 20\%]. In Fig. 7(a), the linguistic values S, MS, M, $\mathrm{ML}$, and $\mathrm{L}$ represent temperature rise small, medium small, medium, medium large, and large, respectively. From Fig. 7(b) and (c), the NL, NS, Z, PS, and PL stand for $\Delta \mathrm{TR}$ and $\Delta I_{\text {fine }}$ negative large, negative small, zero, positive small, and positive large, respectively. Except for the two fuzzy subsets (trapezoidal MFs are considered) at the outmost ends, symmetric triangles with equal bases and 50\% overlap with adjacent MFs are chosen. 


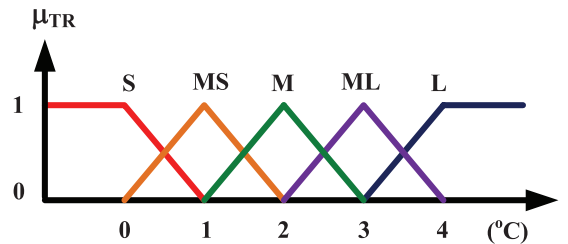

(a)

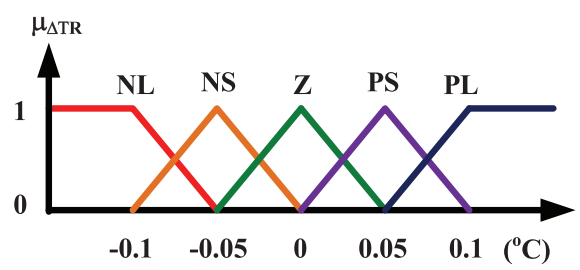

(b)

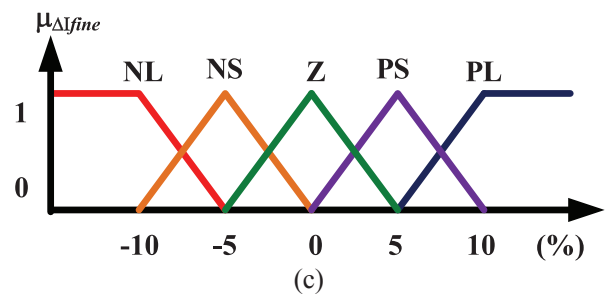

Fig. 7. MFs corresponding to (a) TR, (b) $\Delta \mathrm{TR}$, and (c) $\Delta I_{\text {fine }}$.

In addition, according to the expert experience and knowledge base, the rule base of the incremental current $\Delta I_{\text {fine }}$ are derived in Fig. 8. From Fig. 8, the rule base consists of 25 IF-THEN inference rules (Rule01 Rule25) to derive the $\Delta I_{\text {fine }}$.To do the fuzzy reasoning, fuzzy logic principles are applied to combine IF-THEN rules from the rule base into a mapping from fuzzy input sets to output sets. For example, the deducing rule can be described as if TR is small and $\Delta \mathrm{TR}$ is negative large, then the $\Delta I_{\text {fine }}$ is positive large (PL, Rule 01) and so on. From Rule01, the fuzzy implication can be interpreted that the electrochemical reaction inside the battery was not severe and the temperature was low. Then the charging current can be increased to accelerate the chargingprocess. In this study, the COS defuzzification is utilized to convert the output subsets with different degrees of MF into quantized outputs. The gravity of the area activated can be computed by

$$
\text { Center }=\frac{\sum_{i=1}^{n} Y\left(X_{i}\right) \cdot X_{i}}{\sum_{i=1}^{n} Y\left(X_{i}\right)}
$$

Where the denominator term is the cumulative sum of each point function value $Y\left(X_{i}\right)$, and the numerator term is the position of each point on the $X$ axis multiplied by the function value $Y\left(X_{i}\right)$.

\section{EXPERIMENTAL RESULTS}

This section provides experimental results and waveform

\begin{tabular}{|c|c|c|c|c|c|}
\hline$\Delta$ TR & S & MS & M & ML & L \\
\hline NL & $\begin{array}{c}\text { PL } \\
\text { (Rule01) }\end{array}$ & $\begin{array}{c}\text { PL } \\
\text { (Rule06) }\end{array}$ & $\begin{array}{c}\text { PS } \\
\text { (Rule11) }\end{array}$ & $\begin{array}{c}\text { Z } \\
\text { (Rule16) }\end{array}$ & $\begin{array}{c}\text { Z } \\
\text { (Rule21) }\end{array}$ \\
\hline NS & $\begin{array}{c}\text { PL } \\
\text { (Rule02) }\end{array}$ & $\begin{array}{c}\text { PS } \\
\text { (Rule07) }\end{array}$ & $\begin{array}{c}\text { PS } \\
\text { (Rule12) }\end{array}$ & $\begin{array}{c}\text { Z } \\
\text { (Rule17) }\end{array}$ & $\begin{array}{c}\text { NS } \\
\text { (Rule22) }\end{array}$ \\
\hline Z & $\begin{array}{c}\text { PS } \\
\text { (Rule03) }\end{array}$ & $\begin{array}{c}\text { PS } \\
\text { (Rule08) }\end{array}$ & $\begin{array}{c}\text { Z } \\
\text { (Rule13) }\end{array}$ & $\begin{array}{c}\text { NS } \\
\text { (Rule18) }\end{array}$ & $\begin{array}{c}\text { NS } \\
\text { (Rule23) }\end{array}$ \\
\hline PS & $\begin{array}{c}\text { Z } \\
\text { (Rule04) }\end{array}$ & $\begin{array}{c}\text { Z } \\
\text { (Rule09) }\end{array}$ & $\begin{array}{c}\text { NS } \\
\text { (Rule14) }\end{array}$ & $\begin{array}{c}\text { NS } \\
\text { (Rule19) }\end{array}$ & $\begin{array}{c}\text { NL } \\
\text { (Rule24) }\end{array}$ \\
\hline PL & $\begin{array}{c}\text { NS } \\
\text { (Rule05) }\end{array}$ & $\begin{array}{c}\text { NS } \\
\text { (Rule10) }\end{array}$ & $\begin{array}{c}\text { NL } \\
\text { (Rule15) }\end{array}$ & $\begin{array}{c}\text { NL } \\
\text { (Rule20) }\end{array}$ & $\begin{array}{c}\text { NL } \\
\text { (Rule25) }\end{array}$ \\
\hline
\end{tabular}

Fig. 8. Derivation of rule base for $\Delta I_{\text {fine }}$.

measurements to verify the correctness and feasibility of the designed charger and proposed charging strategy. Test results obtained by the studied remaining capacity with fuzzy TR control (RCFTC) charging, remaining capacity charging (RCC), and conventional $\mathrm{CC}-\mathrm{CV}$ method are analyzed and compared to emphasize the effectiveness and performance boost of the devised scheme in terms of temperature mitigation, charging efficiency, and life cycle. Fig. 9 shows the implemented charger prototype and the main menu of the developed GUI. From Fig. 9(a), the prototype consisits of a SBC-based power circuit with a MCU control core, the SOC and temperature guage ICs with communication protocoal interfaces, and the 4S2P battery pack under charge. The GUI, constructed by the LabVIEW software as illustrated in Fig. 9(b), shows the records of the pack voltage $\left(\mathrm{V}_{\text {bat }}\right)$, charging current $\left(\mathrm{I}_{\text {bat }}\right)$, battery external temperature $\left(T_{\text {bat }}\right)$ and room temperature $\left(T_{\text {amb }}\right)$, calculated temperature rise (TR) and 2-second temperature rise $(\Delta \mathrm{TR})$, and the remaining SOC (RSOC) online during the charging phase. To verify the designed charger, the waveforms of the output current $\left(\mathrm{I}_{\mathrm{o}}\right)$, voltage $\left(\mathrm{V}_{\mathrm{o}}\right)$, two gating signals $\left(\mathrm{V}_{\mathrm{GS} 1}, \mathrm{~V}_{\mathrm{GS} 2}\right)$ of the power switches generated by the MCU, and the efficiency are measured. The input voltage is $24 \mathrm{~V}$. Fig. 10 (a) and (b) show the measured $\mathrm{V}_{\mathrm{GS}}$ and $\mathrm{V}_{\mathrm{GS} 2}$ waveforms when the $\mathrm{I}_{\mathrm{o}}$ is $4.4 \mathrm{~A}$ and the $\mathrm{V}_{\mathrm{o}}$ is equal to the minimal and maximum voltages of the battery pack, 12 $\mathrm{V}$ and $16.8 \mathrm{~V}$, respectively. Obviouly, the charger current can maintain stable output in the variation range of the pack voltage. The measured waveforms prove that the circuit functions completely meet the demand of design specifications. The measured efficiency of the charger is depicted in Fig. 10(c). It can be observed that the design requirement with charger efficiency above $90 \%$ has been achieved in all load output range due to the use of the synchronous rectifier has reduced the conduction losses significantly. The maximum efficiency is $94.39 \%$ that occurs at near $17 \mathrm{~W}$ output power.

Two variable steps of the incremental current $\Delta I_{\text {fine }}$ (i.e. $\Delta I_{\text {fine } \_10 \%}$ and $\Delta I_{\text {fine } \_20 \%}$ ) were studied for the proposed RCFTC charging method to further check and clarify the effect of the temperature rise suppression. Fig. 11 illustrates the regulation mechanism of charging currents for different charging strategies. The variation of the generated TR obtained from different charging methods was shown in Fig. 12. The maximum and 


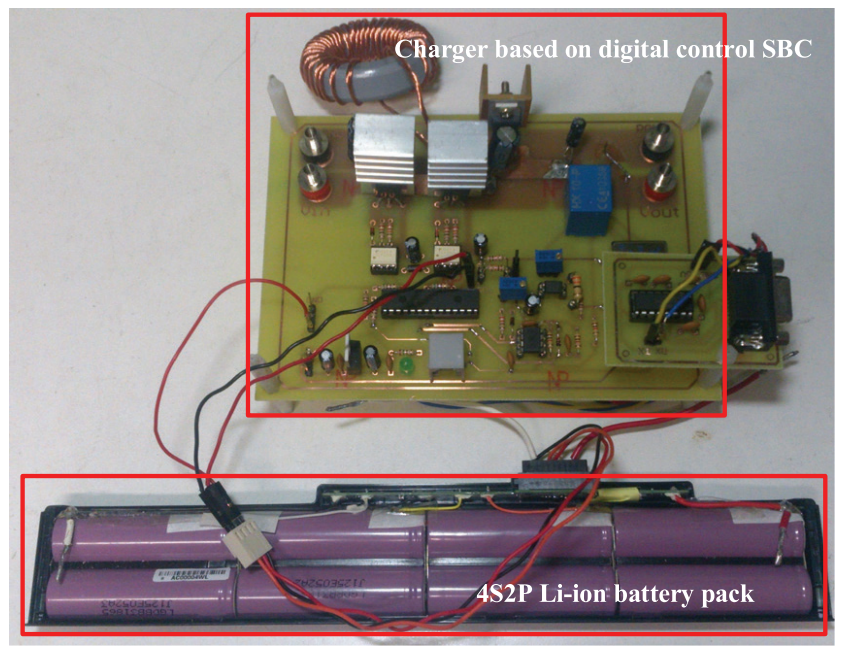

(a)

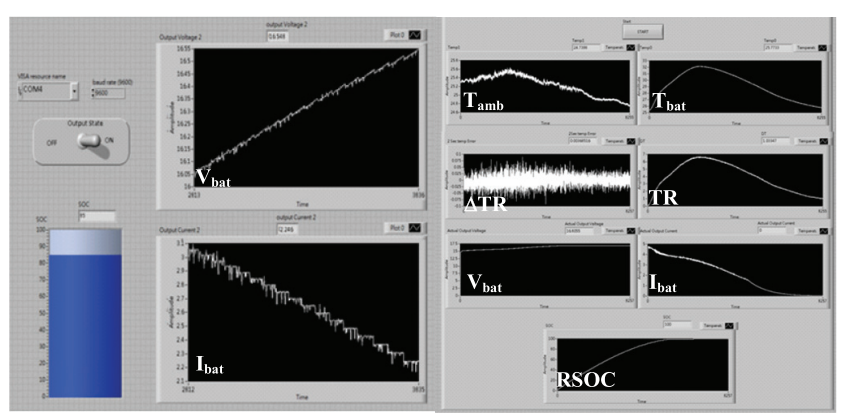

(b)

Fig. 9. (a) The implemented charger prototype, (b) The developed GUI.

average TRs obtained by different charging methods in three tests were tabulated in TABLE V. The charging time (CT), charging capacity $\left(\mathrm{C}_{\mathrm{c}}\right)$, discharge capacity $\left(\mathrm{C}_{\mathrm{d}}\right)$, and charging efficiency $\left(\eta_{c}\right)$ measured with different charging approaches are summarized in TABLE VI. Where the charging efficiency $\eta_{c}$ is defined as the ratio of the discharge capacity to capacity charged into battery during charging process. It can be observed that, from Fig. 11, in the initial stage of charging, the magnitude of the charging current modulation of the proposed RCFTC methods (for steps of $\Delta I_{\text {fine } 10 \%}$ and $\Delta I_{\text {fine } 20 \%}$ ) is less than other methods, thus drastic electrochemical stresses can be avoided. On the other hand, in spite of the full-charge terminated time is slightly longer than that of the counterpart methods, however, in the later phase of charging, the magnitude of the charging current regulation of the proposed RCFTC method is larger than other methods, so as to shorten the charging time. Therefore, the provided adaptive charging current profile can accomplish the research objectives successfully to subdue battery's TR and aging phenomenon. Accordingly, from Fig. 12, under the control of the TR suppression, the proposed RCFTC with $20 \%$ $\Delta I_{\text {fine }}$ step shows the remarkablere lieved effect on temperature rise and the charging efficiency also outperforms those of other counterpart methods obtained.

Furthermore, from TABLE V, as comparing the average TR of the three studied methods (RCC, RCFTC with $\Delta I_{\text {fine } 10 \%}$ and

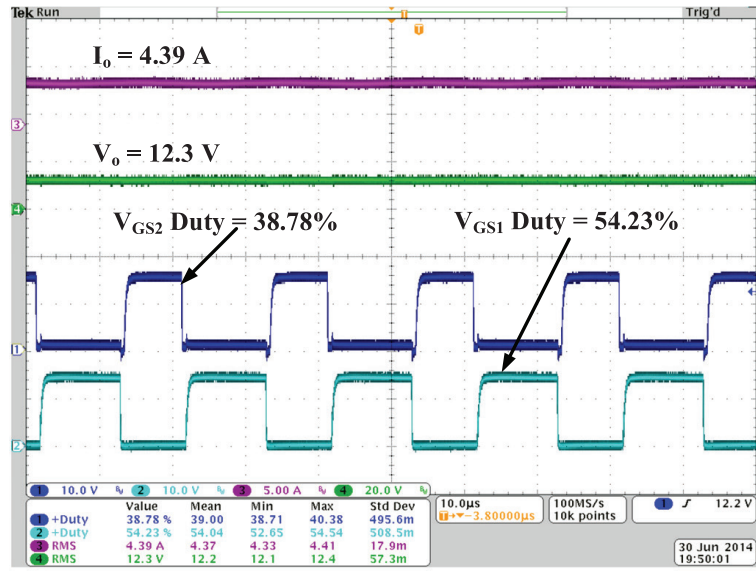

(CH1:10 V/div, CH2:10 V/div, CH3:5 A/div, CH4:20 V/div)

(a)

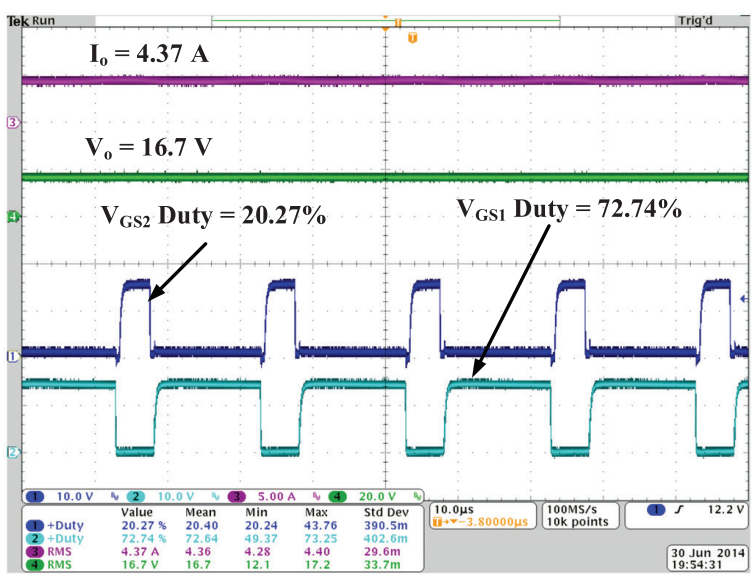

(CH1:10 V/div, CH2:10 V/div, CH3:5 A/div, CH4:20 V/div)

(b)

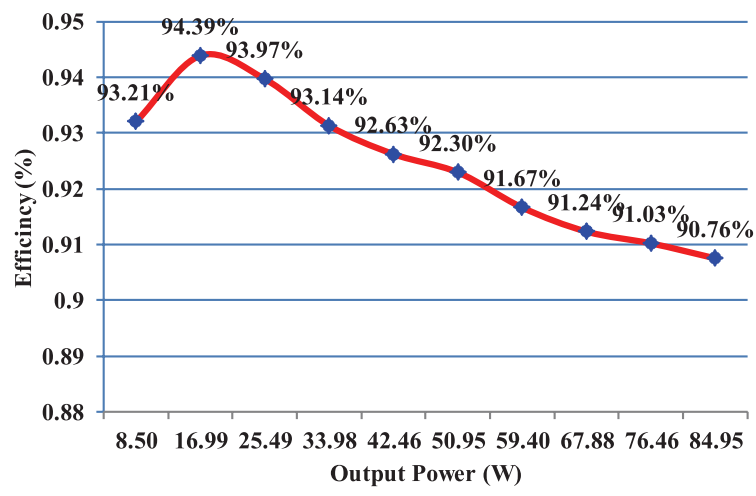

(c)

Fig. 10. (a) Measured waveforms at $12 \mathrm{~V}$ output voltage, (b) Measured waveforms at $16.8 \mathrm{~V}$ output voltage, (c) Measured conversion efficiency of the utilized synchronous buck converter.

$\left.\Delta I_{\text {fine } 20 \%}\right)$ with that of the conventional CC-CV method, the average TRs have reduction of $18.5 \%, 23.2 \%$ and $31.24 \%$, respectively. Obviously, the experimental results exactly reflect the theoretical argument and effectiveness of the proposed charging method. It is noted that, refer to TABLE V and VI, although the 
TABLE V

Maximum and Average TRs Obtained by Different Charging Methods

\begin{tabular}{ccccccccc}
\hline \hline \multicolumn{2}{c}{$\mathrm{CC}-\mathrm{CV}$} & \multicolumn{2}{c}{$\mathrm{RCC}$} & \multicolumn{2}{c}{ RCFTC with $\Delta I_{\text {fine_10\% }}$} & RCFTC with $\Delta I_{\text {fine } \_20 \%}$ \\
\hline Test no. & Max. TR $\left({ }^{\circ} \mathrm{C}\right)$ & Avg. TR $\left({ }^{\circ} \mathrm{C}\right)$ & Max. TR $\left({ }^{\circ} \mathrm{C}\right)$ & Avg. TR $\left({ }^{\circ} \mathrm{C}\right)$ & Max. TR $\left({ }^{\circ} \mathrm{C}\right)$ & Avg. TR $\left({ }^{\circ} \mathrm{C}\right)$ & Max. TR $\left({ }^{\circ} \mathrm{C}\right)$ & Avg. TR $\left({ }^{\circ} \mathrm{C}\right)$ \\
1 & 9.382 & 5.451 & 7.328 & 4.550 & 7.232 & 4.338 & 6.634 & 3.879 \\
2 & 9.567 & 5.547 & 6.954 & 4.454 & 7.081 & 4.231 & 6.310 & 3.661 \\
3 & 9.495 & 5.551 & 7.527 & 4.480 & 6.857 & 4.140 & 6.500 & 3.839 \\
Avg. & 9.481 & 5.516 & 7.270 & 4.495 & 7.057 & 4.236 & 6.481 & 3.793 \\
\hline \hline
\end{tabular}

TABLE VI

Measured CT, Charging Capacity $\left(\mathrm{C}_{\mathrm{C}}\right)$, Discharging Capacity $\left(\mathrm{C}_{\mathrm{D}}\right)$, and Charging Efficiency $\left(\eta_{\mathrm{C}}\right)$

\begin{tabular}{cccccccccccccccccc}
\hline \hline \multicolumn{1}{c}{$\mathrm{CC}-\mathrm{CV}$} & \multicolumn{1}{c}{$\mathrm{RCC}$} & \multicolumn{1}{c}{ RCFTC with $\Delta I_{\text {fine } 10 \%}$} \\
\hline no. & $\mathrm{CT}(\mathrm{s})$ & $\mathrm{C}_{\mathrm{c}}(\mathrm{Ah})$ & $\mathrm{C}_{\mathrm{d}}(\mathrm{Ah})$ & $\eta_{\mathrm{c}}(\%)$ & $\mathrm{CT}(\mathrm{s})$ & $\mathrm{C}_{\mathrm{c}}(\mathrm{Ah})$ & $\mathrm{C}_{\mathrm{d}}(\mathrm{Ah})$ & $\eta_{\mathrm{c}}(\%)$ & $\mathrm{CT}(\mathrm{s})$ & $\mathrm{C}_{\mathrm{c}}(\mathrm{Ah})$ & $\mathrm{C}_{\mathrm{d}}(\mathrm{Ah})$ & $\eta_{\mathrm{c}}(\%)$ & $\mathrm{CT}(\mathrm{s})$ & $\mathrm{C}_{\mathrm{c}}(\mathrm{Ah})$ & $\mathrm{C}_{\mathrm{d}}(\mathrm{Ah})$ & $\eta_{\mathrm{c}}(\%)$ \\
1 & 7376 & 4.650 & 4.456 & 95.84 & 8461 & 4.665 & 4.541 & 97.35 & 8504 & 4.550 & 4.450 & 97.80 & 8765 & 4.661 & 4.549 & 97.60 \\
2 & 7392 & 4.662 & 4.452 & 95.51 & 8369 & 4.657 & 4.535 & 97.39 & 8651 & 4.695 & 4.564 & 97.22 & 8849 & 4.663 & 4.558 & 97.75 \\
3 & 7403 & 4.646 & 4.455 & 95.90 & 8216 & 4.657 & 4.537 & 97.38 & 8687 & 4.735 & 4.616 & 97.50 & 8839 & 4.651 & 4.562 & 98.09 \\
Avg. & 7390 & 4.653 & 4.455 & 95.75 & 8349 & 4.660 & 4.538 & 97.37 & 8614 & 4.660 & 4.544 & 97.51 & 8818 & 4.658 & 4.556 & 97.81 \\
\hline \hline
\end{tabular}

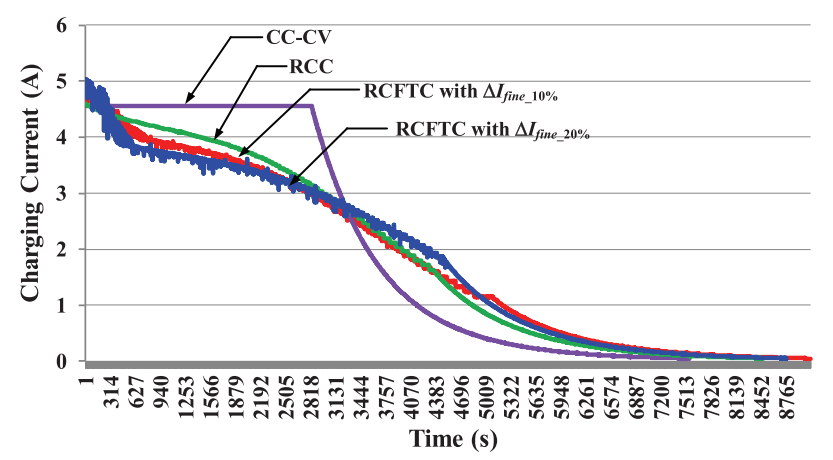

Fig. 11. Regulation of the charging current for different charging methods.

traditional CC-CV method has the shortest charging time, the temperature is high and the charging efficiency is low. The ratio of the RCC charging time to the $\mathrm{CC}-\mathrm{CV}$ charging time, i.e. the CTR is 0.885 , which is close to the expected 0.9. The CTRs of the RCFTC with $\Delta I_{\text {fine_1 } 10 \%}$ and $\Delta I_{\text {fine } 20 \%}$ methods are 0.858 and 0.838 , respectively. In addition, due to the less TR leads to the less energy loss and aging effect. Hence, the average charging efficiencies of the studied methods, as shown in TABLE VI, have $1.62 \%, 1.76 \%$ and $2.06 \%$ of improvements respectively as compared with that of the conventional CC-CV method. Therefore, the RCFTC charging mechanism proposed in this paper can effectively improve the charging efficiency and reduce the most temperature rise.

Finally, to prove the performance of the proposed method, battery cycling test was conducted. The studied RCFTC with $\Delta I_{\text {fine } 10 \%}$ and conventional CC-CV charging methods have been run to evaluate their service time. Two brand new cells with identical nominal capacity $(2200 \mathrm{mAh})$ produced by the same manufacturer are used. Both cells were put into the thermostatic containerin which the operating temperature is maintained at $25^{\circ} \mathrm{C}$ to control the impact of the temperature factor on cycle

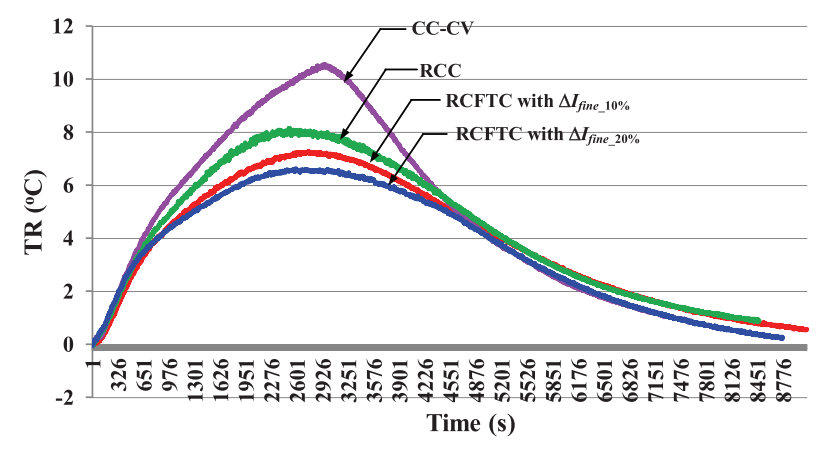

Fig. 12. Measured TR with different charging methods.

life. Test conditions of one cycle period are set up as follows: for conventional CC-CV method, a 1-C current is used to charge one cell in $\mathrm{CC}$ mode, and then a CV mode is applied to fully charge battery. The next, discharge with $0.1 \mathrm{C}$ is conducted until the discharge cut-off voltage is reached. Analogously, the proposed RCFTC with $\Delta I_{\text {fine } 10 \%}$ is run to fully charge the other cell, and then discharge with $0.1 \mathrm{C}$ is done until the discharge cut-off voltage is reached. Fig. 13 illustrates the estimated relationship between RSOC drop (in \%) and cycle numbers. From Fig. 13, the cycling numbers of the proposed RCFTC and CCCV methods when the capacity drop to $97.3 \%$ of the original capacity are 151 and 96, respectively. Although the test has not been run until the battery capacity drops to the specified unusable level (e.g. $80 \%$ ), yet under normal situation, the trend of capacity drop will remain fixed in the long-term cycling test with the same charging/discharging patterns. Consequently, the charging algorithm proposed in this paper can be estimated to provide $57.3 \%$ more cycle-life count than that of the conventional $\mathrm{CC}-\mathrm{CV}$ method. The comparison result of the estimated cycle number test again demonstrates that the high temperature rise has severe impact on battery lifetime. 


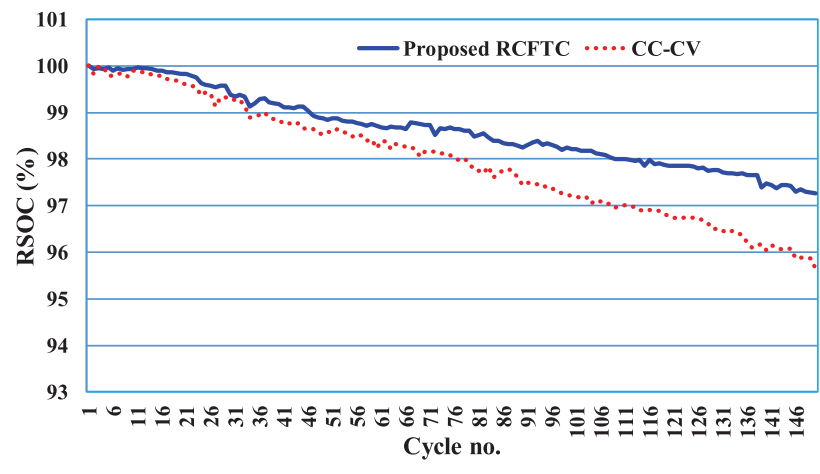

Fig. 13. Comparison of cycle life test between the proposed and the conventional CC-CV methods.

\section{Conclusions}

A digitally-controlled Li-ion battery charger with an adaptive charging strategy has been studied and developed in this paper. The devised charger can dynamically generate the desired charging profile depending on the battery SOC state and temperature variation, that is, the temperature changes of the battery and ambient have been considered in the proposed method. Accordingly, the proposed remaining capacity charging with fuzzy temperature control approach can avoid using high C-rate current to charge battery with high RSOC, and thus the phenomenon of the battery aging aggravation due to the extreme electrochemical stress can also be subdued.The power stage of the charger is implemented by the synchronous-rectified buck converter to further reduce the conduction loss. The firmware and GUI of the proposed system are constructed by a low-cost micro controllercore and LabVIEW software.

Experimental results validate the feasibility and effectiveness of the proposed charger and charging control strategy. The largest $31.24 \%$ reduction of the average temperature rise, $2.06 \%$ improvement of the charge efficiency, and estimated $57.3 \%$ increase in cycle-life count have been accomplished, while maintaining reasonable charging time, as comparedwith the conventional CC-CV method. In addition, without need to build the exhaustive battery model, depending on the change in charging condition, the proposed strategy has taken the nonlinearity of the battery electrothermal behavior and the circuit parameter non-ideality into consideration to effectively achieve the temperature rise mitigation and lifespan extension through charging current dynamic regulation using fuzzy-based decision-making procedure. On the other hand, the proposed charging strategy reaches the charging performance melioration at the cost of a longer charging time needed than that of the CC-CV method, even though the CTR above 0.9 is chosen and the charging time increase still lies in an acceptable range. Accordingly, the future work will focus on exploring the optimum charging profile to substitute for the curve-fitting function in (8). Then a multi-objective function consisting of the charging time, energy loss, and temperature rise will be formulated and solved through advanced optimization algorithms to obtain the best trade-off among the competing objectives for efficient charging management.

\section{REFERENCES}

[1] S. Habib et al., "A comprehensive study of implemented international standards, technical challenges, impacts and prospects for electric vehicles," IEEE Access, vol. 6, pp. 13866-13890, 2018.

[2] V. del Razo and H. A. Jacobsen, "Smart charging schedules for highway travel with electric vehicles," IEEE Trans. on Transportation Electrification, vol. 2, no. 2, pp. 160-173, June 2016.

[3] L. Lu, X. Han, J. Li, J. Hua, and M. Ouyang, "A review on the key issues for lithium-ion battery management in electric vehicles," Journal of Power Sources, vol. 226, pp. 272-288, Mar. 2013.

[4] A. Stippich et al., "Key components of modular propulsion systems for next generation electric vehicles," CPSS Trans. Power Electronics and Applications, vol. 2, no. 4, pp. 249-257, Dec. 2017.

[5] M. A. Hannan, M. M. Hoque, A. Hussain, Y. Yusof, and P. J. Ker, "State-of-the-art and energy management system of Lithium-ion batteries in electric vehicle applications: issues and recommendations," IEEE Access, vol. 6, pp. 19362-19378, 2018.

[6] R. Xiong, J. Cao, Q. Yu, H. He, and F. Sun, "Critical review on the battery state of charge estimation methods for electric vehicles," IEEE Access, vol. 6, pp. 1832-1843, 2018.

[7] M. Yilmaz and P. T. Krein, "Review of battery charger topologies, charging power levels, and infrastructure for plug-in electric and hybrid vehicles," IEEE Trans. Power Electron., vol. 28, no. 5, pp. 21512169, May 2013.

[8] V. Monteiro et al., "Experimental validation of a novel architecture based on a dual-stage converter for off-board fast battery chargers of electric vehicles," IEEE Trans. Vehicular Technology, vol. 67, no. 2, pp. 1000-1011, Feb. 2018

[9] I. Subotic, N. Bodo, and E. Levi, "Single-phase on-board integrated battery chargers for EVs based on multiphase machines," IEEE Trans. Power Electronics, vol. 31, no. 9, pp. 6511-6523, Sept. 2016.

[10] K. Liu, K. Li, Z. Yang, C. Zhang, and J. Deng, "An advanced Lithium-ion battery optimal charging strategy based on a coupled thermoelectric model," Electrochimica Acta, vol. 225, no. 5, pp. 330-344, Jan. 2017.

[11] C. Zhang, K. Li, and J. Deng, "Real-time estimation of battery internal temperature based on a simplified thermoelectric model," Journal of Power Sources, vol. 302, pp. 146-154, Jan. 2016.

[12] F. Hoffart, "Proper care extends Li-ion battery life," Power Electron. Technol. Mag., vol. 34, no. 4, pp. 24-28, Apr. 2008.

[13] C. H. Lin, C. Y. Hsieh, and K. H. Chen, "A Li-ion battery charger with smooth control circuit and built-in resistance compensator for achieving stable and fast charging," IEEE Trans. Circuits Syst. I, Reg. Papers, vol. 57, no. 2, pp. 705-712, Feb. 2010.

[14] B. M. Conlon, "How much capability do electric vehicles need to meet customer demands? Viewpoint," IEEE Electrification Magazine, vol. 5, no. 1, pp. 4-73, March 2017.

[15] R. Shi, S. Semsar, and P. W. Lehn, "Constant current fast charging of electric vehicles via a dc grid using a dual-inverter drive," IEEE Trans. Industrial Electronics, vol. 64, no. 9, pp. 6940-6949, Sept. 2017.

[16] S. A. El-Batawy and W. G. Morsi, "Optimal design of secondary distribution system considering electric vehicles high-power residential fast chargers," IET Generation, Transmission \& Distribution, vol. 11, no. 14, pp. 3475-3484, 2017.

[17] K. M. Tsang and W. L. Chan, "Current sensorless quick charger for lithium-ion batteries," Energy Conversion and Management, vol. 52, no. 3, pp.1593-1595, 2011.

[18] P. H. L. Notten, J. H. G. Op het Veld, J. R. G. van Beek, "Boostcharging Li-ion batteries: A challenging new charging concept", Journal of Power Source, vol. 145, no. 1, pp. 89-94, Feb. 2005.

[19] L. R. Chen, J. J. Chen, N. Y. Chu, and G. Y. Han, "Current pumped battery charger," IEEE Trans. Ind. Electron., vol. 55, no. 6, pp. 24822488, Jun. 2008.

[20] L. R. Chen, C. S. Liu, and J. J. Chen, "Improving phase-locked battery charger speed by using resistance-compensated technique," IEEE Trans. Ind. Electron., vol. 56, no. 4, pp. 1205-1211, Apr. 2009.

[21] L. R. Chen, "Design of duty-varied voltage pulse charger for improv- 
ing Li-ion battery-charging response," IEEE Trans. Ind. Electron., vol. 56, no. 2, pp. 480-487, Feb. 2009.

[22] L. R. Chen, "A design of an optimal battery pulse charge system by frequency-varied technique," IEEE Trans. Ind. Electron., vol. 54, no. 1, pp. 398-405, Feb. 2007.

[23] T. Ikeyaa, N. Sawadab, J. I. Murakamic, K. Kobayashi, M. Hattori, N. Murotani, S. Ujiie, K. Kajiyama, H. Nasu, H. Narisoko, Y. Tomaki, K. Adachi, Y. Mita, and K. Ishihara, "Multi-step constant-current charging method for an electric vehicle nickel/metal hydride battery with highenergy efficiency and long cycle life," J. Power Sources, vol. 105 , no. 1, pp. 6-12, 2002.

[24] P. C. Lin, Y. H. Liu, Y. H. Liu, J. K. Chen, and C. H. Chen, “A fully digital rapid charger for electric scooters," in Proc. Eighteenth Symp. Electrical Vehicles, 2001, Session D7A, pp. 1-13.

[25] J. W. Huang, Y. H. Liu, S. C. Wang, and Z. Z. Yang, "Fuzzy-controlbased five-step Li-ion battery charger," in Proc. IEEE Power Electronics and Drive Systems Conf., Nov. 2009, pp. 1547-1551.

[26] F. J. Lin, M. S. Huang, P. Y.Yeh, H. C. Tsai, and C. H.Kuan, "DSPbased probabilistic fuzzy neural network control for Li-ion battery charger," IEEE Trans. Power Electron., vol. 27 no. 8, pp. 3782-3794, Aug. 2012.

[27] M. Charkhgard and M. Farrokhi, "State-of-charge estimation for lithium-ion batteries using neural networks and EKF," IEEE Trans. Ind. Electron., vol. 57, no. 12, pp. 4178-4187, Dec. 2010.

[28] L. R. Chen, R. C. Hsu, and C. S. Liu, "A design of a grey-predicted Li-ion battery charge system," IEEE Trans. Ind. Electron., vol. 55, no. 10 , pp. 3692-3701, Oct. 2008.

[29] H. Surmann, "Genetic optimization of a fuzzy system for charging batteries," IEEE Trans. Ind. Electron., vol. 43, no. 5, pp. 541-548, Oct.1996.

[30] S. C. Wang and Y. H. Liu, "A PSO-based fuzzy-controlled searching for the optimal charge pattern of Li-ion batteries," IEEE Trans. Ind. Electron., vol. 62, no. 5, pp. 2983-2993, May 2015.

[31] S. Bashash, S. J. Moura, J. C. Forman, and H. K. Fathy, "Plug-in hybrid electric vehicle charge pattern optimization for energy cost and battery longevity," J. Power Sources, vol. 196, no. 1, pp. 541-549, 2011.

[32] Y. H. Liu, J. H. Teng, and Y. C. Lin, "Search for an optimal rapid charging pattern for lithium-ion batteries using ant colony system algorithm," IEEE Trans. Ind. Electron., vol. 52, no. 5, pp. 1328-1336, Oct. 2005

[33] A. Abdollahi et al., "Optimal battery charging, Part I: Minimizing time-to-charge, energy loss, and temperature rise for OCV-resistance battery model," Journal of Power Sources, vol. 303, pp. 388-398, Jan. 2016.

[34] C. Zhang et al., "Charging optimization in lithium-ion batteries based on temperature rise and charge time," Applied Energy, vol. 194, pp. 569-577, 2017.

[35] H. Fang, Y. Wang, and J. Chen, "Health-aware and user-involved battery charging management for electric vehicles: linear quadratic strategies," IEEE Transactions on Control Systems Technology, vol. 25, no. 3, pp. 911-923, May 2017.

[36] C. Zou, X. Hu, Z. Wei, T. Wik, and B. Egardt, "Electrochemical estimation and control for lithium-ion battery health-aware fast charging," IEEE Transactions on Industrial Electronics, vol. 65, no. 8, pp. 66356645, Aug. 2018.

[37] H. E. Perez, X. Hu, S. Dey, and S. J. Moura, "Optimal charging of Liion batteries with coupled electro-thermal-aging dynamics," IEEE
Transactions on Vehicular Technology, vol. 66, no. 9, pp. 7761-7770, Sept. 2017.

[38] Y. H. Liu and Y. F. Luo, "Search for an optimal rapid-charging pattern for Li-ion batteries using the Taguchi approach," IEEE Trans. Ind. Electron., vol. 57, no. 12, pp. 3963-3971, Dec. 2010.

[39] Y. H. Liu, C. H. Hsieh, and Y. F. Luo, "Search for an optimal five-step charging pattern for Li-ion batteries using consecutive orthogonal arrays," IEEE Trans. Energy Convers., vol. 26, no. 2, pp. 654-661, Jun. 2011.

[40] C. L. Liu, Y. S. Chiu, Y. H. Liu, Y. H. Ho, and S. S. Huang, "Optimization of a fuzzy-logic-control-based five-stage battery charger using a fuzzy-based Taguchi method," Energies, vol. 6, no. 7, pp. 35283547, 2013.

[41] M. Yu, Y. Barsukov, and M. Vega, "Theory and implementation of impedance track ${ }^{\mathrm{TM}}$ battery fuel-gauging algorithm in bq2750x family," TI. Application Report, 2008

[42] Microchip Technology Inc, "dsPIC33FJ06GS101/X02 and dsPICF J16GSX02/X04," [Online]. Available: //http://www.microchip.com.

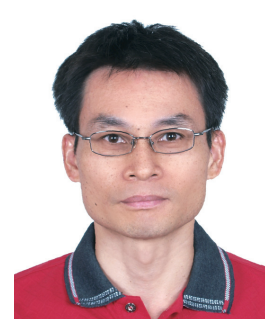

Shun-Chung Wang received the Ph.D. degree in electrical engineering from National Taiwan University, Taipei, Taiwan, in 1995.

$\mathrm{He}$ is currently with the Department of Electrical Engineering, Lunghwa University of Science and Technology, Taoyuan, Taiwan. His current research interests include power electronics and their applications.

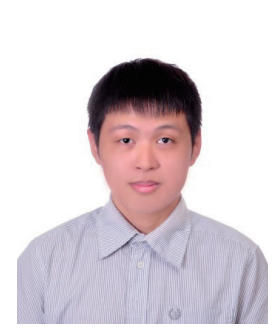

Guan-Jhu Chen was born in Taichung, Taiwan, R.O.C., in 1990. He received the B.S. degree in electrical engineering from Kun Shan University in 2012, and M.S. degree in electrical engineering from National Taiwan University of Science and Technology (NTUST) in 2014. He is currently pursuing a Ph.D. degree in the department of electrical engineering at NTUST. His research interests include power electronics, digital power control and Li-ion battery charging algorithm.

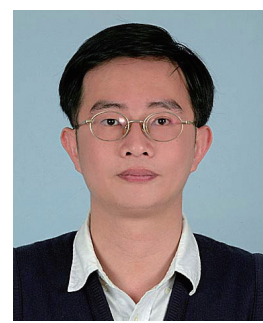

Yi-Hua Liu received the Ph.D. degree in electrical engineering from the National Taiwan University, Taipei, Taiwan, in 1998. He joined the Department of Electrical Engineering, Chang-Gung University, Taoyuan, Taiwan, in 2003. He is currently in the Department of Electrical Engineering, National Taiwan University of Science and Technology, Taipei, Taiwan. His current research interests include the areas of power electronics and battery management. 